\title{
Significaciones de mass media en preparatorianos y universitarios indígenas emigrados a Monterrey
}

\section{Significance of mass media in mid-higher education and university indigenous students inmigrated to Monterrey}

Juan Antonio Doncel de la Colina ${ }^{1^{*}}$ (iD (http://orcid.org/0000-0002-7779-027X)
Recibido el 1 de diciembre de 2015. Aceptado el 7 de junio de 2016.

*Autor para correspondencia: Juan Antonio Doncel de la Colina, correo electrónico:jdoncel@u-erre.mx

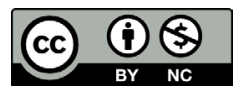

Todos los contenidos de Estudios Fronterizos se publican bajo la licencia Creative Commons Atribución no comercial 2.5 México, y pueden ser usados gratuitamente para fines no comerciales, dando el crédito a los autores y a la revista Estudios Fronterizos.
${ }^{1}$ Universidad Regiomontana, Facultad de Humanidades y Ciencias Sociales, Monterrey, Nuevo León, México, correo electrónico: jdoncel@u-erre.mx

\section{Resumen}

El reciente pero intenso flujo de migrantes indígenas al estado fronterizo mexicano de Nuevo León, ha convertido a esta región en la principal receptora del país de población indígena. Partiendo de la hipótesis de que el ingreso de estos jóvenes indígenas a los niveles educativos medio-superior y superior incide marcadamente en el proceso de transformación de su identidad étnica, hondamos en la comprensión del uso y significaciones que estos estudiantes indígenas dan a ciertos medios de comunicación de masas. Desde un enfoque metodológico cualitativo, a partir de la realización de entrevistas en profundidad analizamos cómo el uso y significaciones diferenciadas del cine, la televisión y la radio simbolizan en muchos sentidos el proceso de transición identitaria por la que pasan estos jóvenes emigrados a Monterrey. Asimismo, identificamos cómo las variables "nivel de estudios" y "grupo étnico" tienen un importante peso explicativo para la comprensión de estos procesos de reconstrucción identitaria.

Palabras clave: significación, mass media, Educación Media Superior, Educación Superior, migrantes indígenas, identidad.

\section{Abstract}

The recent but intense flow of indigenous migrants to the bordering state of Nuevo Leon has become this region to the main recipient of indigenous population in México. On the basis of the hypothesis that the entry of young indigenous to higher educational levels markedly affects the process of transformation of their ethnic identity, we dig here in understanding the uses and meanings that these indigenous students give to certain mass media. From a qualitative methodological approach, on the basis of in-depth interviews we analyze how the differentiated uses and meanings of film, television and radio symbolize in

CÓMO CITAR: Doncel, J. A. (2016). Significaciones de mass media en preparatorianos y universitarios indígenas emigrados a Monterrey [Significance of mass media in mid-higher education and university indigenous students inmigrated to Monterrey]. Estudios Fronterizos, 17(34), 137-158, https://doi.org/10.21670/ref.2016.34.a08 
many senses the process of identity transition of these young emigrated to Monterrey. Also, we identify how the variables "level of studies" and "ethnic group" have an explicative important weight for the understanding of these identitary reconstruction process.

Keywords: significance, mass media, mid-higher education, higher education, indigenous migrants, identity.

\section{Introducción}

El reciente pero intenso flujo de migrantes indígenas al estado mexicano de Nuevo León, flujo compuesto por migrantes provenientes en mayor medida de estados como San Luis Potosí y Veracruz (Olvera, Doncel y Muñiz, 2014), ha convertido a esta región en la principal receptora del país de población indígena (CDI, 2011). Este contingente humano se caracteriza no solo por su importante peso cuantitativo, sino también por su diversidad cultural, pues en este estado habitan inmigrantes hablantes de 56 lenguas indígenas mexicanas (Estrada, 2010). El reto que plantea la adaptación social y cultural de estos nuevos pobladores del área metropolitana de Monterrey debe leerse desde diversos planos: político, social, cultural, económico y educativo.

Consideramos que el ámbito educativo constituye el espacio idóneo para realizar un análisis socio-antropológico que trate de dar cuenta de la forma y dirección que adquieren estos procesos de interacción y de integración (o segregación) social, pues es en este espacio donde el individuo debe afrontar de manera más controlada y profunda su proceso de aculturación.

Dada la escasa atención, tanto social como política, prestada a la inclusión de la población indígena en los niveles superiores de educación, unido a que es en el acceso a estos niveles educativos donde esta población encuentra un obstáculo más abrupto, decidimos circunscribir nuestro análisis a aquellos inmigrantes indígenas que han logrado acceder a la Educación Media Superior (EMS) o a la Educación Superior (Es) en Nuevo León. Partiendo de la hipótesis de que el ingreso de estos jóvenes a los niveles educativos superiores incide marcadamente en el proceso de transformación de su identidad étnica, planteamos un ambicioso proyecto con el que pretendemos analizar los procesos de construcción identitaria en estos estudiantes a partir de cinco agentes socializadores: la familia, la comunidad, la escuela, el ámbito laboral y los medios de comunicación de masas.

La decisión de centrarnos en estos agentes socializadores viene avalada por el respaldo empírico dedicado al análisis de la influencia de estos agentes sobre la construcción de la identidad. Por una parte, el papel de la familia y de la escuela en la construcción de la identidad (ya sea social, étnica, de género, de clase...) es esencial por suponer los espacios en los que se desarrollan las etapas de la socialización primaria (Berger y Luckman, 1993). Unas veces por separado y otras conjuntamente, el análisis de estos dos agentes ha sido abordado en diversos estudios empíricos (por ejemplo, Echavarría, 2003; Mieles y García, 2010).

La ampliación al ámbito laboral, espacio considerado más que para comprender su influencia sobre la construcción de la identidad para la elaboración de las representaciones sociales de Moscovici (1961) en el ámbito de ciertas profesiones, vino aconsejado por el dato emanado de un estudio sobre la integración de los estudiantes indígenas al nivel educativo medio superior en Nuevo León (Olvera, Doncel y Muñiz, 2014). 
Según la encuesta realizada en este diagnóstico socioeducativo, para el $64.6 \%$ de los estudiantes indígenas su actividad principal era el trabajo. Además, la mayor parte del restante $35.4 \%$ que afirmó que el estudio era su actividad principal, también desempeñaba otras actividades laborales. Es decir, la influencia del ámbito escolar, en este caso, no se podía comprender cabalmente sin considerar la influencia del ámbito laboral.

Similar razonamiento debemos plantear para justificar el salto que damos desde el análisis de la familia al de la comunidad. Desde el campo de la antropología social se han dado muestras cómo la vida comunitaria entre los pueblos indígenas americanos no puede ser desvinculada fácilmente de la vida familiar. Un buen ejemplo de la manera en que estos vínculos deben ser estudiados holísticamente, incluso con los jóvenes indígenas que actualmente emigran a zonas urbanas, lo encontramos en el trabajo de Mónica Chávez, (2013).

Por último, respecto al caso de los medios de comunicación y su papel en la construcción de la identidad étnica también ha estado presente de manera prolífica entre los estudiosos, comunicólogos y/o antropólogos, en el ámbito académico latinoamericano (Doncel, 2016).

Los cada vez más numerosos estudios que se están desarrollando para tratar de comprender cómo los indígenas americanos usan o son usados por los medios masivos de comunicación se centran principalmente en dos preocupaciones fundamentales: primero en la forma en la que el indígena es estereotipado y en que esta imagen estereotipada es interiorizada por el mestizo (Nahmad, 2007; CDI, 2006; Muñiz, 2013; Moreno, 2010); y segundo, la utilización de los modernos medios de comunicación por parte de los indígenas como forma de representación de la propia identidad y/o como herramienta de lucha política (Espinosa 1998; Esteinou, Chavez y Peniche 2002; Cisneros, 2006; Castells, 2003; Flores, 2005; Zamorano, s.f.; Baca-Feldman, 2016).

En definitiva, todos los agentes socializadores considerados aquí como factores explicativos en los procesos de reconstrucción de identidades étnicas deben ser considerados conjuntamente, dándoles el peso específico que le corresponda a cada uno de ellos. En este sentido, tal y como expone Smith, refiriéndose, directa o indirectamente, a casi todos los agentes considerados por nosotros:

La formación de la identidad étnica es un proceso multidimensional y dinámico, en donde la integración de la etnicidad en las percepciones del sí mismo depende de: (a) aspectos socioculturales como el estatus social, la estructura, tamaño y organización de los grupos étnicos particulares, así como de las relaciones interétnicas a lo interno de las sociedades; (b) el contexto inmediato, como la familia, la escuela, la zona de residencia y los grupos de pares y (c) los factores interindividuales ligados a la identidad personal que incluyen el desarrollo particular de capacidades cognitivas y emocionales, las inclinaciones y gustos personales y la autoestima (Smith, 2002, p. 79).

Comenzamos ofreciendo en este artículo los primeros hallazgos que corresponden a la etapa de este proyecto de investigación que se refiere al papel que juegan los medios de comunicación de masas. Concretamente, para alcanzar el objetivo general de analizar la distancia simbólica que media entre el auto-reconocimiento étnico de estos estudiantes y la representación de los indígenas mexicanos que en los medios de comunicación de masas se proyectan, proponemos empezar por ahondar en la comprensión del uso y las significaciones que los estudiantes indígenas de niveles superiores de educación emigrados a la Zona Metropolitana de Monterrey dan a ciertos medios de comunicación de masas. 
Para el logro de este objetivo hemos planteado un enfoque metodológico de carácter cualitativo, sirviéndonos de una de las herramientas propias de los estudios etnográficos: la entrevista en profundidad. Estas entrevistas fueron realizadas entre los meses de septiembre y diciembre de 2014, con la implicación de estudiantes que cursaban en este periodo la materia Métodos Cualitativos de Investigación de la licenciatura en Comunicación en la Facultad de Humanidades y Ciencias Sociales de la Universidad Regiomontana.

El guion de las entrevistas en profundidad fue organizado en bloques temáticos para cada uno de los diferentes medios de comunicación de masas considerados y, en un bloque conclusivo, para la cuestión específica de la identidad. Concretamente, tras las preguntas referidas al consumo y gusto por los medios de comunicación en general, se realizaron preguntas en torno al uso y valoración de la televisión, el cine, la radio, las redes sociales, la prensa y la publicidad. Las respuestas que son analizadas en este trabajo son las que se refieren a los medios más utilizados por los entrevistados, así como los significados dados a estos medios expresados abiertamente por el entrevistado o deducidos implícitamente en el discurso por el propio investigador.

Este guion fue aplicado a 29 informantes, atendiendo a las siguientes variables para seleccionar una muestra significativamente diversa: nivel de estudios (preparatoria o universidad), tipo de preparatoria (general o técnica), carrera que estudia o estudió, situación escolar (en proceso, egresado o trunco), edad, género y grupo étnico. La muestra, no probabilística, fue de tipo intencionada, la cual es, a juicio de García (1995), la más adecuada para estudios antropológicos y etnográficos con poblaciones reducidas y de las que el investigador dispone de un amplio conocimiento subjetivo. Asimismo, la estrategia que seguimos nos acerca al muestreo por cuotas, de tal modo que es el propio investigador el que decide qué cantidad de casos con características tipificadas representan suficientemente a la población estudiada (García, 1995). Así, de entre los 29 entrevistados podemos encontrar casos significativos con características diversas (hombres y mujeres, preparatorianos y universitarios, diversos grupos étnicos, etc.).

Sobre estas variables se priorizó la separación de estudiantes de preparatoria frente a los universitarios, por considerarse a priori que la razón de analizar separadamente a preparatorianos de universitarios, a adolescentes de jóvenes, parte de la idea de que la edad adolescente constituye una etapa de la vida en la que la construcción de la identidad se convierte en el problema central de la personalidad, la cual se construye en gran medida a partir de la comparación con los pares y desde cierto sentimiento de rechazo de lo propio (Díaz, 2006). Es decir, la construcción de la identidad en estos dos momentos de desarrollo de la persona es necesariamente distinta (consideración que, como veremos a lo largo de este trabajo, se empieza a corroborar a posteriori). Directamente relacionada con el factor edad, esta separación se materializa en la realización de entrevistas a nueve estudiantes de preparatoria, con 18.1 años de edad promedio, y a 20 estudiantes universitarios, con un promedio de edad de 26.4 años.

En la atención a la variable género, al igual que en el caso de los entrevistados universitarios, aparecen sobrerrepresentadas las mujeres, pues las dos terceras partes de nuestra muestra están compuestas por informantes de género femenino. No obstante, en el caso de esta y del resto de variables consideradas contamos con un panorama lo suficientemente heterogéneo como para poder afirmar que hemos trabajado con una muestra tan diversa como el universo al que pretende caracterizar. Así, en nuestra muestra hemos incluido informantes que han estudiado en instituciones públicas y privadas, en preparatorias generales y técnicas, estudiantes en proceso, truncos y egresados, estudiantes de carreras diversas (Ciencias Sociales, Ciencias Humanas, Ingenierías, Ciencias Económicas y de la Administración, Ciencias de la Salud, etc.). 
Mención aparte merece la distribución de nuestra muestra por grupo étnico, según la cual el $76 \%$ del total de nuestros informantes son de etnia náhuatl $(48 \%)$ o tének (28\%). En un primer momento parecería que el peso específico de estas dos etnias están sobrerrepresentadas, sin responder a la diversidad étnica a la que nos referíamos al principio de esta introducción, pero si observamos la distribución por etnias de los hablantes de lengua indígena en Nuevo León para el año 2010 (INEGI, 2010), podemos concluir que esta sobrerrepresentación en la muestra coincide con la mayor presencia cuantitativa en Nuevo León de la población de etnia náhuatl (66\%) y tének (18\%). Para el resto de grupos étnicos contamos con informantes que ejemplifican la situación de algunas de las etnias minoritarias en Nuevo León (concretamente, mixteco, mixe, tzotzil, mazateco y totonaco).

Para la delimitación de nuestro universo de estudio hemos considerado que todos los sujetos deben cumplir con los siguientes criterios: haber cursado, por lo menos, un semestre completo de alguno de los dos niveles educativos considerados (a fin de que haya tenido tiempo de interiorizar mínimamente su proceso de adaptación escolar); que haya estudiado en un centro educativo ubicado en el Zona Metropolitana de Monterrey (área en la que se concentra más del 90\% de la población del Estado); que haya emigrado desde una comunidad indígena (para que se pueda dar un auténtico proceso de reconstrucción de la identidad étnica) y que sea indígena. En este último punto surge la dificultad esencial para un estudio cuyo objetivo principal se asienta sobre la construcción subjetiva de la identidad: ¿qué es un indígena?

Dado que la respuesta a esta pregunta aspiramos a ofrecerla al final y no al principio de nuestra investigación más amplia, unido a la exigencia metodológica de definir en términos operativos a quién vamos a considerar indígena y, en consecuencia, integrante de nuestro universo de estudio, hemos decidido servirnos inicialmente de un criterio objetivo y difícilmente interpretable. Se trata del criterio que utiliza la Comisión Nacional para el Desarrollo de los Pueblos Indígenas (CDI, 2011), la cual considera indígena a todo aquel que cumple con alguna de estas condiciones: hablar una lengua indígena (nosotros hemos añadido la condición de que sea su lengua materna), vivir o haber vivido con parientes que hablen una lengua indígena o haber vivido en una comunidad indígena de origen. El criterio más subjetivo por el que podríamos habernos decidido, la autoadscripción étnica, planteaba un serio inconveniente, pues esto nos obligaría a excluir de nuestro universo a todo aquél que no se considerase a sí mismo indígena, lo que nos impediría profundizar en una problemática esencial entre la población indígena nuevo leonesa: la negación de la propia identidad étnica y el consecuente ocultamiento de esta identidad.

El trabajo está estructurado en cinco partes claramente diferenciadas. Primeramente se presenta la introducción, en la segunda de ellas se establecen las bases teóricas que dan soporte a nuestro proyecto de investigación, sustento epistemológico caracterizado por la interdisciplinariedad y por el protagonismo del paradigma interaccionista simbólico. En la tercera parte se realiza un repaso por los estudios realizados en España y Latinoamérica que abordan la problemática de la identidad étnica y los medios de comunicación de masas. Enseguida, se exponen los hallazgos de nuestra investigación asentados mayormente sobre el uso y significación de algunos medios especialmente relevantes en este contexto: el cine/video, televisión y radio. Finalizamos con las conclusiones. 


\section{Fundamentación teórica}

El enfoque teórico que ha de sustentar epistemológicamente nuestro trabajo cabalga entre los campos multidisciplinares de la Antropología Social, la Sociología de la Cultura y la Psicología Social. En concreto, la Antropología Social podrá aportar a nuestros intereses particulares tanto su propio enfoque metodológico, ideado para el estudio de pequeñas comunidades humanas, como el sostén teórico y conceptual, principalmente para adentrarnos en la problemática de la identidad social y de las dinámicas propias del contacto intercultural (ya sea el contacto vicario a través de los medios de comunicación de masas o el contacto directo en el ámbito educativo de socialización).

Dado que nuestro foco de atención está puesto en los procesos de construcción de identidades étnicas determinados tanto por el substrato cultural de origen como por la sociedad de acogida a través de los medios de comunicación de masas, sumado al hecho de que entendemos que el intercambio cultural se desprende en esencia de un proceso de comunicación simbólica, será el paradigma interaccionista simbólico el que fundamente epistemológicamente nuestra investigación.

Este paradigma, con una presencia significativa tanto en la Antropología como en la Psicología Social, ha sido desarrollado especialmente desde la Antropología Simbólica. La Antropología Simbólica, propuesta desde su vertiente cultural por Clifford Geertz y en su vertiente social por Victor Turner a mediados de los años sesenta, propone que la cultura no reside únicamente en la dimensión intersubjetiva, sino que se corporiza en símbolos públicos mediante los cuales los sujetos comunican entre sí su visión del mundo, sus valores, etc. (Ortner, 1984).

Dado el vínculo esencial entre la construcción de la identidad étnica y la subjetivación de la cultura (o el proceso de aculturación), nos interesa subrayar aquí el enfoque propuesto por Geertz, de quien nos ha de servir su ya clásica definición de cultura:

Creyendo con Max Weber que el hombre es un animal inserto en tramas de significación que él mismo ha tejido, considero que la cultura es esa urdimbre y que el análisis de la cultura ha de ser, por lo tanto, no una ciencia experimental en busca de leyes, sino una ciencia interpretativa en busca de significaciones (Geertz, 2005, p. 20).

Una visión de la cultura como fenómeno esencialmente dinámico es lo que nos aporta Geertz, al igual que Berger y Luckmann, con su explicación del triple proceso dialéctico de interiorización-exteriorización-objetivación para la construcción social de la realidad (Berger y Luckmann, 1993). Esta visión, según la cual la cultura no aparece únicamente como agente coercitivo frente a un sujeto social pasivo, coincide con nuestra concepción de la identidad en tiempos de la globalización: la identidad entendida también como una elaboración esencialmente dinámica y cambiante. Así es como lo plantea Stuart Hall, partiendo del posicionamiento de Foucault (1968) según el cual se da un desplazamiento del interés desde el sujeto cognoscente hacia la preocupación por una teoría de la práctica discursiva (que no implica una abolición del sujeto, pero sí una reconceptualización del mismo):

En los últimos años se registró una verdadera explosión discursiva en torno al concepto «identidad» (...) La deconstrucción se ha realizado en el interior de varias disciplinas, todas ellas críticas, de una u otra manera, de la noción de una identidad integral, originaria y unificada (...) En el lenguaje del sentido común, la identificación se construye sobre la base del reconocimiento de algún 
origen común o unas características compartidas con otra persona o grupo con un ideal, y con el vallado natural de la solidaridad y la lealtad establecidas sobre este fundamento. En contraste con el «naturalismo» de esta definición, el enfoque discursivo ve la identificación como una construcción, un proceso nunca terminado: siempre «en proceso» (Hall, 2011, p. 13, 15).

No obstante al planteamiento de Hall, referente básico de los Estudios Culturales desde una perspectiva crítica, partimos de la base de que la identidad étnica se asienta, todavía hoy, sobre un área de intersubjetividad hasta cierto punto objetivable (Giddens, 1993), a pesar de la extrema elasticidad a la que obliga la ineludible tensión dialéctica entre tradición y modernidad. Esta permanencia de la etnicidad era explicada por Fredrik Barth hace casi 40 años y creemos que en el México actual mantiene su vigencia:

Las distinciones étnicas no dependen de una ausencia de interacción y aceptación sociales; por el contrario, generalmente son el fundamento mismo sobre el cual están construidos los sistemas sociales que las contienen. En un sistema social semejante, la interacción no conduce a su liquidación como consecuencia del cambio y la aculturación; las diferencias culturales pueden persistir a pesar del contacto interétnico y de la interdependencia (Barth, 1976, p. 10).

Así pues, nuestra propuesta parte de un planteamiento de la identidad profundamente relacional, planteamiento que bebe del trabajo de interaccionistas como Goffman (2004) y su enfoque dramatúrgico, pues, como sugiere Charry: "Goffman aunque no habla de la identidad propiamente dicha, la considera como la mismidad, en tanto como producto de la persona actuante en situaciones sociales" (Charry, 2006, p. 200). De este modo, debemos subrayar el proceso de construcción bidireccional de la cultura y, en consecuencia, de la identidad social. Por otra parte, también debemos resaltar que las culturas están vivas y en constante recreación, gracias al poder performativo del actor social y a pesar del poder coercitivo de aquellas sobre estos.

\section{Antecedentes empíricos}

El interés por la relación entre medios de comunicación de masas y los procesos de construcción (o destrucción o reconstrucción o deconstrucción...) de identidades étnicas entre los pueblos originarios latinoamericanos se ha venido desarrollando desde finales del siglo pasado. Por ejemplo, el trabajo de Espinosa, publicado en 1998, se centra en un análisis del uso político de los medios de comunicación de masas de los pueblos indígenas de la Amazonia Peruana, a través de tres grupos étnicos y en diferentes momentos históricos. Más concretamente, Espinosa escribe acerca de: la radio y el proceso de construcción de la identidad étnica y creación de organizaciones políticas representativas entre los shipibo; la vinculación al Estado a través de la televisión para la redefinición del concepto de identidad nacional en un contexto de conflicto armado de los asháninka y de los aguaruna; y los usos de internet del pueblo Asháninka. La principal conclusión de este autor es que el uso de estos medios hace más visibles a las comunidades indígenas y les permite actuar políticamente en diferentes espacios públicos (Espinosa, 1988).

Tanto el estudio de Espinosa como la mayor parte de la literatura científica que aborda este fenómeno parten de la problemática de la confrontación política, de la ideología de la dominación sobre los pueblos indígenas desde una hegemónica e indefinida sociedad 
mestiza y de la lógica de la reivindicación identitaria y cultural. En este sentido, en el contexto mexicano, el levantamiento del Ejército Zapatista de Liberación Nacional en 1994 en Chiapas motivó, en el ámbito académico, la elaboración de una serie de artículos que caminaban, en delicado equilibrio, entre el texto científico y la reivindicación política. Entre estos textos, hubo los que se referían a la reivindicación insatisfecha del acceso y apropiación de las comunidades indígenas de algunos medios de comunicación de masas (Esteinou, Loera y Peniche, 2002) o al papel esencial de los medios para la reivindicación de la identidad indígena, entendida como lucha social y movimiento emancipador ante una situación estructural de marginación (Cisneros, 2006).

De entre los estudios que analizan los usos dados a los medios de comunicación de masas por parte de las comunidades indígenas, destacan los que focalizan su interés en un medio al que también nosotros vamos a prestar especial atención en este artículo: el cine (o video $)^{2}$. Este extendido interés, ya sea el centrado en las nuevas formas de hacer cine desde la mirada del indígena o en el que pone el acento en el cine como reproductor de estereotipos respecto a este colectivo humano, obedece en gran medida a un momento de auge creciente del cine y el video indígena en Latinoamérica (Castells, 2003). Así, encontramos trabajos que van desde la reflexión etnometodológica a partir del papel de productos elaborados por videastas locales de una comunidad maya de Guatemala para su proceso de la reconstrucción social y cultural tras una guerra civil (Flores, 2005), hasta los que se centran en la función del cine hecho por indígenas en su triple papel de rompedor de estereotipos, difusor de sus lenguas o reivindicador político a través de la "ficción subversiva" (Castells, 2003).

En este mismo sentido, Nahmad (2007) reflexiona en torno a la lucha de poder, dominación y resistencia, a través de las representaciones visuales del indígena latinoamericano proyectados por las producciones cinematográficas en tres contextos: primera mitad del siglo XX en México; desde la década de los sesenta en Bolivia; el uso actual del video por diversos indígenas de Latinoamérica. Esta tensión dialéctica entre la proyección hegemónica de las representaciones y la elaborada por el propio indígena se transmuta en la arena donde se construye la identidad, como expone Nahamad, tanto la del indígena como la del mestizo:

Desde la invención/conquista de América la imagen y representación de los indígenas significó una querella por la identidad, no únicamente la de ellos, sino también por las otras identidades a las que se enfrentaron (las de los colonizadores). En este nuevo siglo se agudiza el conflicto, ya que la generación de representaciones sintetiza las disputas por el ejercicio del poder. Por ello es necesario interpretar tanto las imágenes generadas por los indígenas, como las construidas sobre ellos, como formas de creación de significados estrechamente relacionados a proyectos políticos y culturales de producción de identidades que, en la mayoría de los casos, entran en controversia (Nahmad, 2007, p. 107).

\footnotetext{
${ }^{2}$ Dado que en muchas de las comunidades indígenas de este país las salas de exhibición no existen, encontrándose la más cercana a una distancia demasiado lejana para que estos indígenas se habitúen a este consumo, surge el video como un medio de comunicación alternativo. Su accesibilidad, cada vez mayor, hace que se incremente su uso entre los jóvenes de estas comunidades (tanto como productores como consumidores), tal y como lo atestigua el hecho de que este medio de comunicación se esté convirtiendo en foco de atención de tantos comunicólogos y antropólogos (muchos de los cuales mencionamos aquí). Así, aunque en cierto modo hay una cierta equivalencia entre el uso y significaciones dadas al cine y al video (como veremos en el apartado de resultados), sin duda cada uno de ellos mantiene sus especificidades técnicas, lo que aconseja seguir haciendo la distinción entre ambos cuando nos refiramos a uno u a otro.
} 
Es en la última afirmación de esta autora, la que se refiere a la necesidad de interpretar las imágenes generadas por los indígenas, unida a la necesidad de adentrarnos en los significados que se atribuyen a estas imágenes desde un punto de vista emic, en la que encontramos justificación para asentar nuestro trabajo empírico sobre el paradigma interaccionista simbólico.

Respecto a la forma en que es interiorizada por la población mestiza la proyección de la imagen estereotipada del indígena a través de los medios de comunicación de masas, en México también se han elaborado varios diagnósticos y análisis comunicológicos. Tal es el caso del trabajo "Percepción de la imagen del indígena en México" (CDI, 2006), estudio en el que se analiza, cuantitativa y cualitativamente, la forma en la que los medios de comunicación de masas difunden estereotipos negativos de los indígenas fomentando su discriminación y el racismo entre jóvenes urbanos (residentes en Monterrey, Guadalajara y Distrito Federal). Una de sus conclusiones más relevantes es el proceso de invisibilización del indígena, así como la visión dicotómica del mismo, dicotomía que oscila entre "lo indígena", base del orgullo nacional y "los indígenas", caracterizados por el desprecio con el que son percibidos.

Una investigación más compleja y profunda es la que se realizó en el estado de Nuevo León, estudio cristalizado en la obra "Medios de comunicación y prejuicio hacia los indígenas" (Muñiz, 2013). También desarrollado para analizar la forma en la que los jóvenes urbanos (regiomontanos, en este caso) reciben e interiorizan la imagen que los medios proyectan del indígena, nuevamente descubrimos que esta imagen presenta una doble cara: la del indígena histórico, casi mítico, representante esencial de la identidad y de la cultura nacionales, frente a la del indígena actual, asociado a la indigencia y al atraso social y cultural.

La trascendencia de este tipo de estudios es indiscutible, habida cuenta de que es un hecho y un problema global que "los medios de comunicación (...) en el mejor de los casos, ignoran la realidad de estos pueblos (indígenas), y en el peor, contribuyen a perpetuar una imagen negativa y folclórica que los relega a la marginación" (Castells, 2003, p. 51). Pero, sin duda, el ejercicio académico que más se acerca al planteamiento que nosotros estamos proponiendo aquí es la elaboración de la tesis doctoral titulada "Procesos de comunicación/educación en contextos de diversidad cultural. Interpelación y reconocimiento en la construcción de subjetividad de jóvenes indígenas wichí en el Chaco Salteño, Argentina" (Bustamante, 2013). Concretamente, nos interesa el capítulo de la obra en la que el autor propone:

Rastrear si el consumo de medios de comunicación constituye un espacio de interpelación y de reconocimiento, es decir, por un lado, en qué medida y de qué forma los medios de comunicación ejercen interpelaciones sobre los jóvenes indígenas (de etnia wichí) de estas comunidades, y por otro lado, si se producen reconocimientos y de qué manera se dan (Bustamante, 2013, p. 326).

Aunque este trabajo presenta serias carencias, como la que supone el hecho de describir superficialmente, sin interpretar ni profundizar en las representaciones e identificaciones de los jóvenes entrevistados (a los que solo realizó tres sencillas preguntas al respecto), sí se alcanzan algunas conclusiones que nos sirven para consolidar nuestros propios hallazgos. Por ejemplo, acerca de la distancia entre la imagen proyectada y la propia autoimagen, Bustamante escribe:

Estos jóvenes (de etnia wichí) pueden reconocerse en dichos medios, a pesar de que lo que allí se muestre no se parezca en nada a los paisajes, la vida y 
las personas de la zona que nos ocupa. Sin embargo, a pesar de que se dé reconocimiento con productos en los cuales las propias prácticas y escenarios no aparecen (...) esta distancia entre lo vivido y lo televisado no es inocua, y opera desvalorizando lo propio en favor de modelos dominantes de estilos de vida, de belleza, etc. (Bustamante, 2013, p. 327).

Es decir, que los jóvenes wichíes entrevistados sí se identifican, sí "muestran valoraciones, adhesiones y prácticas en las que se observa el reconocimiento ante las interpelaciones de la televisión" (Bustamante, 2013, p. 337) ante una imagen deformada de sí mismos, lo que, en este caso, provoca una desvalorización de lo propio, de lo vivido cotidianamente.

Hasta aquí, todos los trabajos que buscan entender, desde diferentes puntos de vista, la relación entre etnicidad y medios de comunicación de masas, se han centrado en el análisis de comunidades indígenas en su propio contexto social y cultural. Son realmente excepcionales los estudios existentes que consideran esta problemática desde la óptica de los indígenas emigrados a las ciudades. La excepción la encontramos en el trabajo de Ros (2004), autor que propone entender los motivos del "olvido" mediático que viven los indígenas guaraníes emigrados del campo a la ciudad, con su consecuente aislamiento respecto al resto de la sociedad, para capacitarlos como comunicadores. El olvido del guaraní emigrado al que se refiere Ros se extiende a un olvido institucional y académico.

Pero no tan sólo están olvidados oficialmente, también son los olvidados de los investigadores, que centran sus estudios en las zonas de origen de los migrantes, consideradas como más «puras» o «auténticas», olvidados de los proyectos de desarrollo estatales y privados, enfocados también hacia las zonas de origen y que pretenden más bien desanimar la migración a la urbe; olvidados de las autoridades municipales (...); olvidados de las demás organizaciones indígenas que desprecian a menudo y denuncian la supuesta «aculturación» de los guaraníes urbanos (Ros, 2004, p.110).

La relación entre este olvido, la emigración a la ciudad y la pérdida de la identidad étnica es explicitada por Ros en la siguiente cita, subrayando el papel determinante de los medios (sobre todo, de nuevo, el de la radio) para combatir este olvido y el consecuente proceso de etnocidio.

Toda esta realidad incide notablemente en la identidad étnica entre los migrantes a la urbe. La pérdida del idioma o del referente territorial son indicadores de una crisis en la definición de su identidad (...) Afianzar la cultura propia significa difundirla, expandirla, hacerla patente incluso a aquéllos que pretenden ignorarla y acallarla. Y para ello, los medios de comunicación, y muy especialmente la radio, por su capacidad de llegar a lugares alejados, donde se encuentra la población indígena, son los más indicados para fortalecer los valores propios (Ros, 2004, pp. 111-112).

Con este repaso del estado de la cuestión podemos alcanzar una doble conclusión: por una parte, contamos con un importante cuerpo de análisis científicos que indican un creciente interés por un fenómeno globalizador irreversible y que afecta hasta a las minorías más periféricas; por otra parte, que estamos ofreciendo un estudio original en su planteamiento, pues es el único que correlaciona las variables identidad étnica, migración urbana, medios de comunicación de masas y niveles superiores de educación. 


\section{Usos y significaciones dadas a los medios de comunicación de masas}

De entre todos los estudiantes entrevistados y atendiendo a los diferentes criterios considerados para la selección de la muestra, hemos encontrado una variable especialmente relevante por su capacidad explicativa: el nivel de estudios (relacionado directamente con la edad promedio). Así hemos decido analizar la mayor parte de los resultados dividiendo a nuestra muestra en dos grupos: los estudiantes de Educación Media Superior (EMS) y los estudiantes de Educación Superior (ES).

En el caso de los estudiantes de EMs, casi todos los entrevistados afirmaron usar con frecuencia el celular, internet y la televisión, al tiempo que ninguno de los entrevistados estudiantes de preparatoria afirmaron leer la prensa y casi ninguno dijo ir al cine o escuchar la radio. En este sentido, la respuesta ofrecida por nuestro informante 1 aparece como una respuesta típica para este sector de nuestra muestra: “(Uso) todos (los medios), menos el periódico y el radio. Me aburre leer y el radio es para señores. Pues, veo la tele a veces, y al cine nunca voy, pero la tele y el internet siempre los uso" (Informante 1, 15 de noviembre de 2014). Hasta aquí parece que los usos de los medios de comunicación de masas responden más bien a la lógica del que vive su edad adolescente en una gran ciudad, y no tanto a una cuestión de etnicidad. Así parece ante una mirada rápida y superficial, pero si nos detenemos en el dato encontramos un matiz que escapa a esta explicación: la afirmación de todos los entrevistados estudiantes de preparatoria de que no van nunca o casi nunca al cine.

En el caso de los universitarios entrevistados el cine sigue siendo el medio menos veces mencionado, pero ya aparecen algunos que lo frecuentan. Igualmente, más de la tercera parte de los entrevistados universitarios afirmó leer, con mayor o menor frecuencia, la prensa escrita, y casi la mitad de los mismos afirmó escuchar la radio. También en torno a la mitad de los universitarios mencionó en primer lugar el uso del celular y en mayor cantidad, aunque con menor frecuencia, el uso de la televisión. El internet, al igual que el caso de los estudiantes de preparatoria, fue el medio más veces mencionado (tres de cada cuatro entrevistados afirmaron utilizarlo).

Pero volviendo a los estudiantes de preparatoria, nos interesa detenernos en la ausencia casi total del hábito de ir al cine. Esta ausencia contrasta marcadamente con los hábitos de consumo medio en México, país que, como constata el Instituto Mexicano de Cinematografía, en 2015 "se ubicó entre los cinco países con mayor asistencia a salas de cine (...). En el ámbito nacional, la asistencia total fue la más alta de los últimos años al registrarse más de 286 millones de boletos vendidos, 46 millones más que en 2014" (IMCINe, 2015, p. 61). A este dato debemos sumar que, tras realizar un análisis de la cartelera del Área Metropolitana de Monterrey, encontramos que la tercera parte de la misma está dedicada a películas del género de terror, cuyo público es fundamentalmente un público adolescente y juvenil, y que la mayor parte de géneros dominantes, como el de superhéroes o las comedias románticas, también se dirige en gran medida a este sector del público. Al igual que en muchas grandes ciudades mexicanas, en Monterrey la actividad de ir al cine es caracterizada como una costumbre muy extendida entre la población adolescente regiomontana, costumbre que debe ser redimensionada si la entendemos como espacio de socialización privilegiado en la edad adolescente. En este sentido, la asistencia a las numerosas salas de proyección dispersas por el área metropolitana de Monterrey por parte de miles de adolescentes acompañados de sus amigos/as y novios/as va más allá del mero consumo de un producto mediático; constituye una costumbre de sociabilización (Simmel, 2014) que contribuye, al favorecer ciertas dinámicas de 
interacción entre pares y entre géneros, a la generación de un sentido de pertenencia y, en último término, de identidad (Konterllnik, 1999; Ayestarán, 1987).

No obstante lo anterior, entre los nueve entrevistados que estaban estudiando preparatoria seis afirmaron de manera contundente no ir al cine y dos dijeron que "a veces" o "rara vez". Además, estos últimos, dijeron que iban al cine no con amigos, sino con familiares (hermanos y/o primos), por lo que tampoco puede considerarse esta actividad como la costumbre de sociabilización a la que nos referíamos más arriba. ${ }^{3}$ Solo una de las entrevistadas para este nivel educativo afirmó ir al cine con cierta frecuencia, aproximadamente una vez al mes, y además hacerlo con sus compañeras de estudios o con las compañeras con las que convive en la residencia religiosa que habita. Ampliando la observación a las tres estudiantes universitarias menores de 20 años (pues, tal y como ya expusimos en la introducción de este artículo, en esta argumentación el factor determinante es, junto al nivel educativo, la edad del informante), encontramos idénticos resultados. Dos de estas entrevistadas afirman que nunca van al cine y una de ellas que va con frecuencia... para llevar a los niños que cuida.

Entrevistador: ¿Vas al cine?

Informante 15: Ay sí, me lleva siempre la señora Gaby.

Entrevistador: ¿En serio?, que padre, ¿cada cuánto tiempo?

Informante 15: A veces vamos mucho, como dos veces al mes... porque hay muchas películas de los niños.

Entrevistador: Entonces, vas con tu jefa y sus hijos.

Informante 15: Sí, porque el señor Alejandro no le gusta tanto en el cine... mejor luego salen y las compra y las ponen en la casa, porque dice que en el cine se duerme, y yo también quisiera (dormir), pero voy con los niños y no me duermo.

Entrevistador: $\mathrm{Y}$ ¿tú no vas con amigos al cine?

Informante 15: Pues es que no, porque ¿a qué horas? Aparte sí me gustan esas de los niños. Está bien.

(Informante 15, 3 de diciembre de 2014).

De esta cita podemos extraer un posible factor explicativo del porqué los adolescentes indígenas no tienen la costumbre de ir al cine: el factor laboral. En este sentido, el dato obtenido en nuestro trabajo de campo es contundente: solo 3 de los 29 entrevistados dijeron no trabajar (tres jóvenes de 15,17 y 18 años que viven con sus padres y se dedican únicamente a estudiar). Este dato, significativo cualitativamente, corrobora los datos, representativos estadísticamente, obtenidos en un estudio previo referido específicamente a estudiantes indígenas de EMs en Nuevo León:

\footnotetext{
${ }^{3}$ Esto nos hace pensar en dos características que estamos detectando entre nuestro universo de estudio y sus respectivas comunidades. Por una parte, aparece una evidente tendencia a la soltería entre los indígenas que deciden estudiar en los niveles superiores de educación. El dato en este sentido es demoledor: en una muestra con 24 años de edad de promedio y con individuos provenientes de culturas donde el matrimonio se suele realizar a edades relativamente tempranas, 26 de los 29 entrevistados son solteros y sin hijos, lo que llevará a plantearnos en otra parte la relación entre la estrategia adaptativa que supondría renunciar a formar la propia familia (o a demorar el momento de fundarla) para poder acceder a los niveles superiores de educación. Por otra parte, también es destacable y vinculada a la relación con familiares cercanos durante el tiempo de ocio, la tendencia de muchas comunidades indígenas de este país a la endogamia. Como expone Carlos Serrano, director del Instituto de Investigaciones Antropológicas de la UNAM, las prácticas endogámicas se generan sobre todo en el ámbito rural y en comunidades indígenas marcadas históricamente por su aislamiento cultural, religioso, económico y/o geográfico, entendiendo Serrano estás prácticas como "expresión de defensa de la identidad cultural" (Serrano, 2010, p. 4). Dada la importancia y la complejidad de estas dos tendencias, estas serán tratadas y analizadas en profundidad en posteriores trabajos.
} 
Un factor negativo y decisivo respecto a la posibilidad de que terminen sus estudios es la condición de migrante de la mayor parte de los alumnos indígenas (92 por ciento) que supone una urgencia laboral y económica (65 por ciento manifiestan trabajar como actividad principal) (Olvera, Doncel y Muñiz, 2014, p. 159).

En la siguiente cita, además de ejemplificar nuevamente esta generalizada ausencia de tiempo libre para asistir al cine (la respuesta en este sentido es idéntica a la anterior: “¿a qué horas?"), también encontramos una significativa y extendida respuesta respecto a cómo es vivida subjetivamente esta práctica.

Entrevistador: Bueno, ¿Vas al cine?

Informante 1: No, y no me gusta. Es muy caro, y me aburren las películas largas. Entrevistador: Ay, ¿y nunca has ido?

Informante 1: Como dos veces... y no me acuerdo, me dormí.

Entrevistador: ¿No ves películas?

Informante 1: ¿A qué horas?, no. Tengo otras cosas.

Entrevistador: ¿Qué otras cosas?

Informante 1: Trabajo... y la prepa, que no me sirve para nada, pero ahí estoy. Y los niños (que cuida). No, yo nomás tele y el celular. No me gusta eso (...).

Entrevistador: Okey, al menos dime ¿Qué tipos de película que no den te gustaría ver en el cine?

Informante 1: Cualquiera, porque son dramáticas y aburridas. No me gustan las películas, no sé qué les ven.

(Informante 1, 15 de noviembre de 2014).

En esta y en muchas otras de las respuestas obtenidas se habla de que las películas en el cine "aburren" o que "duermen", lo que nos habla de cierta desmotivación, la cual parte, según nuestra interpretación, de la percepción de una costumbre entendida como ajena (costumbre entendida como ajena por el hecho de que la mayor parte de los indígenas que constituyen la muestra provienen de comunidades en las que no existe esta costumbre, pues no hay cines comerciales). Si bien es cierto que durante el trabajo de campo hemos podido constatar que en Cinema Cuauhtémoc (ubicado en la Alameda de Mariano Escobedo, simbólico punto de encuentro dominical en el Área Metropolitana de Monterrey de inmigrantes indígenas provenientes de otros estados de la República Mexicana) se está asimilando esta costumbre entre indígenas de todas las edades (también adolescentes con sus amigos/as y novios/as), de modo que sí encontramos esta dinámica de sociabilización entre adolescentes, también es cierto que, como nos han expuesto varios de los estudiantes entrevistados, los que se suelen reunir aquí son mayormente trabajadores, pero no tantos estudiantes. Así pues, parece que la receptividad hacia una costumbre propia de la sociedad de acogida no es factor suficiente para adoptar dicha costumbre, sino que se tiene que dar también una posibilidad económica y temporal.

Cuando escribimos que en las comunidades de los entrevistados no existe la costumbre adolescente de ir al cine con amigos, no significa que no existan otras formas de experimentar el visionado colectivo de una película (que, al fin y al cabo, es en lo que consiste eso que llamamos "ir al cine").

Si bien es cierto que en la mayor parte de los casos consultados no existe ninguna sala de proyección comercial en la comunidad de origen, también es cierto que surgen espontáneamente usos locales en torno al visionado colectivo de películas, práctica que acarrea implicaciones de orden social, cultural e incluso económico. Esto lo vemos con 
claridad en la narración que nos ofrece nuestro informante 14, mujer universitaria, de etnia tének y proveniente de una pequeña comunidad de la Huasteca Potosina.

Informante 14: Allá no hay cine... Bueno, hay pero súper lejos.

Entrevistador: Allá no hay cine comunitario ni nada de eso ¿no?

Informante 14: De repente en mi casa hacíamos el cine, porque teníamos una tele así chiquita, de blanco y negro. Entonces, como éramos la única familia que teníamos tele, todos los vecinitos se venían y mi mamá hacía negocio con eso, porque les decía 'vayan a traerme agua'... la acarreaban del pozo... 'cada quien dos botes de agua' y todos iban y ahora sí, a ver el programa... no sé, del Chavo, por ejemplo... cosas de esas.

Entrevistador: ¿Y se juntaban muchos?

Informante 14: Bastantes... y la telecita así miniatura y hasta que explotó ya nadie fue (risas). Sí pero así...

Entrevistador: ¿Cuántos más o menos iban a verla? ¿20 personas?

Informante 14: Más o menos, puros jovencitos y jovencitas.

Entrevistador: Traían el agua y veían la tele.

Informante 14: Ajá (afirmando) y veían la tele.

Entrevistador: Qué bueno.

Informante 14: (risas) Sí, mi mamá...

Entrevistador: ¿Y qué programas veían?

Informante 14: Bueno... era el Chavo del ocho, por ejemplo, que estaba en ese tiempo y que estaba padre. Ya luego ya todos estuvieron adquiriendo sus teles y cada y... y... Por ejemplo, los que habían comprado una tele más o menos que era con video-casetera ya le ponía películas y cobraba a toda la comunidad y ya iban, pero telecita así chiquita.

Entrevistador: ¿Y ya era como en el cine pero en la tele?

Informante 14: Ajá (afirmando).

Entrevistador: ¿Y... va ahí la gente a comer palomitas?

Informante 14: ¡No, no, no! (con extrañeza), eso no, no habían palomitas (...).

Entrevistador: Pero bueno era una forma de reunirse, ¿no?

Informante 14: Sí de... y era, no era de escoger la cartelera así como que... ahí era la única película que tuvieran y si te gustaba pues te ibas a colar ahí.

Entrevistador: ¿Y a nadie se le ocurrió poner un cine como negocio?

Informante 14: A nadie se le ha ocurrido.

Entrevistador: O comprar un proyector.

Informante 14: Hasta la fecha no, no han puesto (nuevamente con extrañeza) (...) No, no, no han hecho eso, ¡ni en la secundaria tienen!, bueno en la secundaria que nos queda ahí cercana no tienen proyector tampoco. Digo, sería buen negocio.

(Informante 14, 23 de noviembre de 2014).

En esta narración apreciamos, entre otras dimensiones, el potencial cohesionador que contiene una pequeña pantalla, potencial que se materializa con especial intensidad en una cultura cuya concepción colectivista de la vida social permite trascender el ámbito público hasta el espacio doméstico, reconvertido en espacio de socialización primaria (entendida esta en su sentido bergeriano) para los más jóvenes de la comunidad. Además de los lazos comunitarios fortalecidos en este improvisado espacio de socialización, también apreciamos el posible germen de un sistema de intercambio de servicios, intercambio que muta en actividad comercial en el momento en que algunos miembros de la comunidad 
con televisión y "video-casetera" empiezan a cobrar. ${ }^{4}$ Esto último nos lleva a imaginar una posible estructuración socioeconómica simbólica en torno a las casas con la posibilidad de ofrecer estos servicios, casas que deben gozar de cierto prestigio a partir de la posesión de bienes de consumo considerados en este contexto como exclusivos.

Otro aspecto de la misma narración nos da la pauta para señalar el impacto de los medios de comunicación de masas sobre ciertas minorías socioculturales. Cuando nuestra informante se refiere al programa que solían ver, se refiere indirectamente a cómo determinado producto mediático dirigido desde la cultura dominante cumple con su papel de agente socializador. En la narración también percibimos cómo el acto de ir al cine es resignificado y la forma en que es llevada a cabo esta práctica adquiere su propia razón de ser (por este motivo por parte de la informante es recibido con extrañeza el planteamiento de acompañar la película con palomitas o de realizarla con un proyector, lo que acercaría la práctica a la forma en la que es llevada a cabo en las ciudades por la sociedad mestiza). El motivo de esta aparente resistencia escapa a nuestro análisis, pues de los datos obtenidos no podemos deducir si esto es el resultado de una situación económica precaria o si responde a factores de orden más simbólico.

Lo que sí podemos resaltar aquí es la significación diferenciada del acto de ir al "cine" en una sociedad urbana y mestiza frente a una sociedad rural e indígena. En todo caso, esta costumbre no es estática, sino que evoluciona a la misma velocidad que lo hacen las tecnologías de la información y comunicación, de tal modo que se generan nuevos hábitos que tendrán que ser soportados por nuevos valores y nuevas cosmovisiones. Esto es un fenómeno que va mucho más allá de los indígenas mexicanos emigrados a Nuevo León, como podemos leer en el trabajo realizado por Bustamente acerca de los wichíes argentinos. En esta cita se alude indirectamente a la resignificación de la práctica de ver televisión entre jóvenes que ya no van al monte y al río, como tradicionalmente se hacía, sino que ven televisión y conviven en torno a ella (con lo que también el espacio doméstico es resignificado):

Los lugares donde los jóvenes entrevistados miran televisión son la casa de los padres en la actualidad y la escuela en el pasado. Distintos autores señalan que históricamente, los wichí realizaron la inmensa mayoría de su vida al aire libre, y que hasta la actualidad las viviendas solo se utilizan para dormir. En los últimos años, en la zona del Pilcomayo salteño, se agregan a esta actividad, el mirar televisión y el uso de ordenadores, aquellos que los tienen (Bustamante, 2013, p. 332).

En la siguiente narración, desarrollada por una estudiante universitaria, oaxaqueña y de etnia mixe, podemos apreciar cómo no siempre los productos mediáticos consumidos colectivamente provienen de los centros de poder económico y cultural. Aquí lo que encontramos son recreaciones de la propia cultura y de las propias tradiciones. Es decir,

\footnotetext{
${ }^{4}$ La comercialización del derecho al acceso a determinados productos audiovisuales a través de la mediación pecuniaria no debe ser vista, ni mucho menos, como una costumbre aislada. Así, podemos encontrar esta costumbre, por ejemplo, entre los wichíes del noroeste de Argentina, aunque en esta ocasión la comercialización de estos servicios favorece el contacto interétnico y el lucro de algunos mestizos a partir de los clientes indígenas:

En aquella época, cuando no había aparatos de televisión en las comunidades, los lugares (donde se reunían a ver televisión) eran algún comercio en los pueblos criollos o en la escuela. Esto último sigue siendo así en las comunidades de monte donde no llega el tendido eléctrico como Pozo La China. Un poblador criollo podía cobrar $50 \mathrm{cc}$ para permitir ingresar a cada persona que quisiera ver televisión. Un entrevistado relató que hace diez o 12 años, cuando era niño, también en la escuela cobraban 25 cc para ver televisión (Bustamante, 2013, p. 329).
} 
se proyecta cierta imagen del nosotros, lo que cumplirá una función de fortalecimiento identitario (o por lo menos, de ciertos aspectos de la identidad comunitaria). Hay dos aspectos más de esta narración que consideramos deben ser remarcados: el papel activo de los miembros de la comunidad en la elaboración del producto mediático, los cuales son estudiantes, y, por otra parte, la convivencia lingüística relativamente armónica en la dimensión mediática, siendo priorizado en ciertas ocasiones el propio idioma mixe sobre el español.

Entrevistador: ¿Ahí en tu comunidad hay cine?

Informante 16: No, no hay cine. Es como si tú quieres proyectar un documental, juntas a la comunidad, les dices que vas a proyectar un video en cierta fecha y depende de los que lo hagan. Pero deben convocar y ahí la proyectan.

Entrevistador: ¿Y sí acude la gente?

Informante 16: Sí, sí acude.

Entrevistador: Entonces me dices que cuando hay un día festivo o fecha especial es esto. ¿Quiere decir que no es tan frecuente?

Informante 16: No, no lo es, por que deben convocar con anticipación.

Entrevistador: ¿Tú también ibas a esos eventos?

Informante 16: Sí, por ejemplo, en navidad, el nacimiento del niño Dios.

Entrevistador: ¿Que otros tipos de películas proyectan?

Informante 16: Actividades que realizan, cultural... proyectan lo grabado, o documentales que estudiantes realizan en la comunidad, son actividades.

Entrevistador: ¿Son en tu lengua o español?

Informante 16: Depende de lo que vayan a proyectar. Por ejemplo, el documental era de mi pueblo, pero el resto es en español. A veces ponen subtítulos en español.

(Informante 16, 4 de noviembre de 2014).

Aquí debemos considerar la particularidad de las comunidades mixes, entre las que encontramos una infrecuente preocupación por la educación de sus hijos unido a un desarrollado orgullo de la propia cultura (Comboni y Juárez, 2012). Resultado de esta inusual preocupación, uno de nuestros informantes clave, presidente de la Federación de Estudiantes Indígenas de la Universidad Autónoma de Nuevo León, afirma que la proporción de estudiantes mixes en el nivel educativo superior es mucho mayor que el de cualquier otro grupo étnico.

Siguiendo con nuestra informante mixe, en la siguiente cita vemos de qué manera la convivencia lingüística a la que nos referíamos más arriba también se da en el medio radiofónico. ${ }^{5}$ No solo esto, sino que en la narración más amplia de esta informante

${ }^{5}$ Nuevamente, el trabajo de Bustamante sobre los wichíes argentinos nos sirve para generalizar nuestros hallazgos, en este caso, el del destacado papel de la radio como agente socializador en las comunidades indígenas:

Como señalamos anteriormente, la radio es el medio masivo de comunicación más presente desde hace ya muchos años en zonas rurales como las comunidades wichí del Pilcomayo salteño. A esto ayudan el accesible costo económico de los receptores de radio, sus pequeñas dimensiones y la posibilidad de usarlo sin red de energía eléctrica. Los contenidos predominantes de las radios locales son música, mensajes rurales y algunas informaciones. Con la excepción de un solo programa los días sábados, los contenidos son en lengua castellana. Son también comunes las muestras de desconfianza por parte de los miembros de las radios locales cuando se llevan mensajes en lengua wichí. En general, no se permiten este tipo de mensajes (Bustamante, 2013, p. 330). 
descubrimos cómo la radio funge como destacado elemento de transmisión y reproducción de la lengua y la cultura en los más pequeños, a lo que debemos sumar de qué forma nos describe y resalta la concienciación de los adultos mixes, convertidos en agentes de control social para el aprendizaje por parte de sus hijos de su propio idioma (Comboni y Juárez, 2012), al contrario de tantos otros grupos étnicos en los que no quieren que sus hijos aprendan su lengua por considerarla como un símbolo de estigma. Un ejemplo que contrasta claramente con el caso mixe es el que nos facilitó nuestra informante 14, de etnia tének, la cual narra en otro momento de la entrevista cómo ella no fue consciente de su propia identidad hasta el momento en que emigró, saliendo de su comunidad y exponiéndose por primera vez al contacto interétnico. Veamos ahora el contenido de la cita de nuestra informante mixe:

Entrevistador: Allá en tu comunidad me mencionaste que hacían transmisiones (radiofónicas) en tu lengua... estos... ¿`son noticias, música...?

Informante 16: Es un poco de todo. Convocar gente, cuentos infantiles, música (...).

Entrevistador: ¿YY son en español?

Informante 16: Sí, son en español (...), pero los niños, cuando cuentan una historia en mi lengua, los niños: atentos. Los adultos no ponen tanta atención, pero los niños sí, porque al último les preguntan qué entendieron y ya cada quien hace su comentario.

Entrevistador: Hay alguna estación que te permita hablar, pasar un aviso...

Informante 16: Ah, sí, por ejemplo, hay una base de datos como un correo, cuando...mmm... 'mando saludos para los familiares González Vázquez' al conductor... 'le mando saludos' y así, o felicitaciones, cumpleaños o también una música de cumpleaños, dedicatorias...

Entrevistador: Pero todo esto desde internet...

Informante 16: Sí, desde internet o Facebook, o la página de la radio.

Entrevistador: Oye súper bien, están muy actualizados.

Informante 16: Sí, es más por el movimiento de los jóvenes. Como ya tienen esa conciencia de mantener la cultura, que no es bueno perderlo porque es lo que nuestros abuelos nos dejaron... si tú perteneces a una cultura hay que saber mantenerlo. Yo si lo dejara me sentiría perdida...lo buscaría, pero sabrías que ya perteneces a un grupo.

(Informante 16, 4 de noviembre de 2014).

En esta cita aparece la función de la radio ya no solo como difusora de la propia cultura y reforzadora de identidades, sino como reforzadora de vínculos sociales a través de la comunicación personalizada de la radio comunitaria. El resultado queda expresado perfectamente al final de la cita, cuando nuestra informante se refiere a que "yo si lo dejara (su cultura) me sentiría perdida...lo buscaría, pero sabrías que ya perteneces a un grupo": un vínculo esencial del sujeto hacia el grupo de referencia y un temor, complementario a este vínculo, de desembocar en la anomia.

\section{Conclusión}

Al principio de este artículo nos proponíamos ahondar en la comprensión del uso y las significaciones que los estudiantes indígenas de niveles superiores de educación 
emigrados a la Zona Metropolitana de Monterrey dan a ciertos medios de comunicación de masas. Decidimos focalizar nuestro análisis en los medios que consideramos con mayor poder explicativo respecto a la forma en la que influyen en los procesos de construcción o reconstrucción de la identidad étnica, así como en las dinámicas de interacción intercultural entre el indígena emigrado y la sociedad de acogida. Así, para este fin, seleccionamos los usos y significados dados al cine, a la televisión o video (entendidos todos ellos como ritual de visualización colectiva) y a la radio.

Especial relevancia le dimos en nuestro análisis a la costumbre de ir al cine entre los adolescentes estudiantes de preparatoria, entendiendo dicha costumbre desde la perspectiva de la sociedad de acogida como esencialmente urbana y mestiza, siendo caracterizada desde este punto de vista como espacio de sociabilización adolescente y, en último término, como importante elemento en la construcción de la identidad social entre los jóvenes regiomontanos.

Pero el hecho de que en el indígena emigrado no exista esa específica cultura cinematográfica, entendida como lo hace el mestizo urbano, no quiere decir que este indígena no le dé una significación diferenciada al acto de "ir al cine". Así, hemos visto que la costumbre equiparable a este acto en sus comunidades de origen viene mediada por la presencia restringida de la televisión. La costumbre de la visualización colectiva de una pequeña pantalla debe ser leída desde diversas dimensiones de análisis. Se trata, en definitiva, de una costumbre propia de estas comunidades indígenas que incide en las dimensiones social (por su función cohesionadora, así como por el hecho de suponer un espacio de socialización primaria), cultural (pues se asienta sobre cierto valor de lo colectivo y sobre otra forma de dimensionar los ámbitos de lo público-privado) y económica (dinamizando una práctica que se convierte en intercambio de servicios y, más adelante, en comercio con mediación pecuniaria). Se trata, en suma, del "cine" en la comunidad de origen entendido como espacio en el que también se construye la identidad comunitaria o étnica.

De aquí resaltamos la práctica de "ir al cine" y su significación diferenciada entre una sociedad urbana y mestiza frente a una sociedad rural e indígena, como la clara expresión de un desencuentro intercultural. En todo caso, ni en la ciudad ni en la comunidad se mantienen las costumbres estáticas en el tiempo, sino que evolucionan a la misma velocidad que lo hace el desarrollo de las tecnologías de la información y comunicación. Así, encontramos que, aun partiendo de un substrato cultural tan diferente, los estudiantes indígenas emigrados a Monterrey empiezan a dar muestras de adaptación a una costumbre en principio extraña, sobre todo entre los estudiantes de Es.

Aun así, en el proceso de cambio vemos cómo los pocos estudiantes de preparatoria que van al cine en Monterrey lo hacen con familiares cercanos, no con amigos, lo que también supone una recreación de la costumbre orientada más a la endogamia de la que proceden que a la exogamia (como es el caso de los adolescentes mestizos y urbanos, quienes van al cine con amigos/as y novios/as antes que con familiares). En este sentido, si bien el factor económico y laboral condiciona la incorporación del indígena a esta costumbre, este factor se muestra rotundamente insuficiente para explicar en su totalidad esta resistencia. Por otra parte, también la tecnología varía las prácticas a las que nos referíamos en las comunidades de origen, de tal modo que se generan nuevos hábitos que tendrán que ser soportados por nuevos valores y nuevas cosmovisiones.

De entre las variables consideradas para nuestra muestra, como ya anticipamos y justificamos en la introducción de este trabajo, el nivel de estudios, considerado junto a la edad, ha resultado de gran importancia para explicar el uso de ciertos medios de comunicación de masas. Así, el hecho de que los jóvenes estudiantes de preparatoria eviten 
el uso de la radio, la lectura de periódicos y la asistencia al cine, contrasta con el mayor uso que de estos medios afirman dar los no tan jóvenes estudiantes y egresados universitarios. Esto se puede leer en un doble sentido: por un lado, el proceso de aculturación que supone comenzar a asistir al cine, hasta cierto punto, con el contenido cultural que le da el regiomontano; y por otro, el reforzamiento de la identidad étnica que implica escuchar programas de radio en su propio idioma, como dijeron hacer muchos de los entrevistados universitarios.

Además de las variables edad y nivel de estudios, a partir del caso de la comunidad mixe que hemos documentado, podemos concluir que también el grupo étnico de pertenencia y la comunidad de origen deben ser considerados importantes factores explicativos de los procesos de construcción de la identidad (comunitaria o étnica). En este sentido, hemos podido comprobar cómo, por una parte, entre los estudiantes universitarios entrevistados, —que leen y se informan más que los de preparatoria— se da una mayor conciencia de la propia identidad étnica; mientras que, por otra parte, lo mismo sucede si comparamos la experiencia de nuestra informante tének frente a la de la informante mixe.

En la narración de la informante tének podemos apreciar cómo en su comunidad de origen reciben los contenidos mediáticos impuestos por la cultura hegemónica (aunque estos contenidos sean resignificados a partir de su propio substrato cultural), de modo que nos encontramos ante un colectivo que vive su etnicidad de manera inconsciente. En este sentido, tal y como mencionamos en el apartado de resultados, una informante tének nos explica que nunca se planteó cuestiones en torno a su identidad étnica hasta que emigró fuera de su comunidad.

Por el contrario, nuestra informante mixe nos narra cómo son sus propios paisanos los que, partiendo de una desarrollada conciencia étnica (más desarrollada aún entre los estudiantes universitarios de su comunidad), acostumbran a construir sus propios productos mediáticos, recreando la propia cultura y las propias tradiciones. Una cuestión que habrá de ser analizada con mayor profundidad en próximas entregas de este proyecto de investigación es la relación entre esta desarrollada conciencia de identidad étnica y la mayor presencia de estudiantes universitarios entre los emigrantes mixes. Parece, en definitiva, que el hecho de que los mixes construyan sus propios productos mediáticos, proyectando la autoimagen que ellos mismos sienten como propia, cumple una importante función de fortalecimiento de la identidad étnica y comunitaria. Esta función fortalecedora de identidades también ha sido explicada a través del uso de la radio, la cual se constituye, por un lado, en destacado elemento de transmisión de la lengua y la cultura mixe y, por otro lado, en reforzadora de vínculos sociales a través del contacto interpersonal que facilita la radio comunitaria.

\section{Referencias}

Ayestarán, S. (1987). El grupo de pares y el desarrollo psicosocial del adolescente. Estudi General, (7), 123-136.

Barth, F. (Comp.). (1976). Los grupos étnicos y sus fronteras. La organización social de las diferencias culturales. México: FCE.

Baca-Feldman, C. (2016). Experiencias resonantes de comunicación en pueblos indígenas de Oaxaca, México. Universitas Humanística, (81), 255-277.

Berger, P. y Luckmann, T. (1993). La construcción social de la realidad. Buenos Aires, Argentina: Amorrortu. 
Bustamante, F. (2013). Procesos de comunicación/educación en contextos de diversidad cultural. Interpelación y reconocimiento en la construcción de subjetividad de jóvenes indígenas wichi en el Chaco Salteño, Argentina (Tesis doctoral inédita). Universidad de Málaga, España.

Castells, A. (2003). Cine indígena y resistencia cultural. CHASQUI. Revista Latinoamericana de Comunicación, (084), 50-57.

CDI [Comisión Nacional para el Desarrollo de los Pueblos Indígenas]. (2006). Percepción de la imagen del indígena en México. Diagnóstico cuantitativo y cualitativo. Recuperado de http://www.cdi.gob.mx/dmdocuments/percepcion_imagen_indigena_mexico.pdf

CDI [Comisión Nacional para el Desarrollo de los Pueblos Indígenas]. (2011). Acciones de gobierno para el desarrollo integral de los pueblos indígenas. Informe 2010. México: Autor.

Charry, C. (2006). Identidad social: interdisciplina y dualidad. En A. Nebbia y M. Mora, Análisis social e identidades (pp. 191-214). México: Plaza y Valdés, Universidad Autónoma Metropolitana.

Chávez, M. (2013). La familia, las relaciones afectivas y la identidad étnica entre indígenas migrantes urbanos en San Luis Potosí. Relaciones. Estudios de historia y sociedad, XXXIV(134), 131-155.

Cisneros, A. (2006). Los indígenas contra la modernidad. El Cotidiano, 21(137), 32-37.

Comboni, S. y Juárez, J. (2012). Discurso y cosmogonía mixe en la construcción de un proyecto educativo: el caso de las IEs Mixes. Universidades, LXII(53), 36-49.

Díaz, J. (2006). Identidad, adolescencia y cultura. Jóvenes secundarios en un contexto regional. Revista Mexicana de Investigación Educativa, XI(29), 431-457.

Doncel, J. A. (2016). Procesos de identificación a través del consumo de telenovelas por parte de preparatorianas y universitarias indígenas emigradas al Área Metropolitana de Monterrey. Corpus. Archivos virtuales de la alteridad americana, 6(1), en prensa.

Echavarría, C. (2003). La escuela: un escenario de formación y socialización para la construcción de identidad moral. Revista Latinoamericana de Ciencias Sociales, Niñez y Juventud, $1(2), 1-26$.

Espinosa, O. (1998). Los pueblos indígenas de la Amazonía peruana y el uso político de los medios de comunicación. América Latina Hoy, 19, 91-100.

Esteinou, J., Chávez, L. y Peniche, M. (2002). La reforma del Estado y el acceso de los pueblos indios a los medios de comunicación. Economía, Sociedad y Territorio, 3(12), 639-673.

Estrada, J. (28 de noviembre de 2010). Miles de indígenas dejan atrás sus pueblos y emigran al norte de México. En cnnMéxico. Recuperado de

http:/ / mexico.cnn.com/nacional/2010/11/28/miles-de-indigenas-dejan-atras-sus-pueblos-y-emigran-al-norte-de-mexico

Flores, C. (2005). Video indígena y antropología compartida: una experiencia colaborativa con videastas maya-q'eqchi' de Guatemala. LiminaR. Estudios Sociales y Humaníticos, 3(2), 7-20.

Foucault, M. (1968). Las palabras y las cosas. Una arqueología de las ciencias humanas. México: Siglo XXI.

García, M. (1995). Socioestadística. Introducción a la estadística en sociología. Madrid, España: Alianza Editorial.

Geertz, C. (2005). La interpretación de las culturas. Barcelona, España: Gedisa.

Giddens, A. (1993). Las nuevas reglas del método sociológico. Crítica positiva de las sociologías interpretativas. Buenos Aires, Argentina: Amorrortu. 
Goffman, E. (2004). La presentación de la persona en la vida cotidiana. Buenos Aires, Argentina: Amorrortu.

Hall, S. (2011). Introducción: ¿quién necesita “identidad”? En S. Hall y P. de Gay (Comps.), Cuestiones de identidad cultural (pp.13-39). Buenos Aires, Argentina: Amorrortu.

imcine. (2015). Anuario Estadístico de Cine Mexicano 2015. México: Autor.

Inegi. (2010). XIII Censo de población y vivienda 2010. Tabulados básicos. México: Autor.

Konterllnik, I. (1999). La participación de los adolescentes: ¿exorcismo o construcción de ciudadanía? En E. Tenti (Comp.), Una escuela para los adolescentes. Materiales para el profesor-tutor (pp. 73-100). Buenos Aires, Argentina: UNICEF.

Mieles, M. y García, M. (2010). Apuntes sobre socialización infantil y construcción de identidad en ambientes multiculturales. Revista Latinoamericana de Ciencias Sociales, Niñez y Juventud, 8(2), 809-819.

Moreno, R. (2010). Indígenas en la ciudad y en la lejanía. La representación diferenciada de los indígenas en el discurso periodístico (El Norte: 1988-2006). En S. Durin (Coord.), Etnicidades urbanas en las Américas. Procesos de inserción, discriminación y politicas multiculturalistas (pp. 253-268). México: Publicaciones de la Casa Chata.

Moscovici, S. (1961). Psicología Social II. Barcelona, España: Paidós.

Muñiz, C. (Coord.). (2013). Medios de comunicación y prejuicio hacia los indígenas. México: Fontamara.

Nahmad, A. D. (2007). Las representaciones indígenas y la pugna por las imágenes. México y Bolivia a través del cine y el video. Latinoamérica. Revista de Estudios Latinoamericanos, (45), 105-130.

Olvera, J., Doncel, J. A. y Muñiz, C. (2014). Indígenas y educación. Diagnóstico del nivel medio superior en Nuevo León. México: U-ERre, UANL, Fondo Editorial Nuevo León.

Ortner, S. (1984). Theory in Anthropology since the Sixties. Comparative Studies in Society and History, 26(1), 126-166.

Ros, J. (2004). Los indígenas olvidados. Comunicar, XII(22), 109-114.

Serrano, C. (4 de agosto de 2010). Con la urbanización, disminuye la endogamia en México. Boletín UNAM-DGCS-460. Recuperado de http://www.dgcs.unam.mx/boletin/ bdboletin/2010_460.html

Simmel, G. (2014). Sociología: estudios sobre las formas de socialización. México: FCE.

Smith, V. (2002). Aportes a la comprensión de la identidad étnica en niños, niñas y adolescentes de grupos étnicos minoritarios. Revista de Ciencias Sociales, II(96), 71-82.

Zamorano, G. (s.f.) Los usos del video comunitario para imaginar un Estado plurinacional. Recuperado de: http://www.bolivianstudies.org/revista/9.1/documentos_ pdf/ZamoranoGabriela42712.pdf

\section{Entrevistas}

Informante 1. (15 de noviembre de 2014). Mujer de etnia tének y estudiante de Educación Media Superior. Entrevistador Estefanía Páez Santelices-Grimaldi. Starbucks de Constitución, Monterrey, Nuevo León.

Informante 14. (23 de noviembre de 2014). Mujer de etnia tének y estudiante universitaria. Entrevistador Julio Alejandro Torres Mendoza. Instalaciones de la Universidad Regiomontana, Monterrey, Nuevo León. 
Informante 15. (3 de diciembre de 2014). Mujer de etnia tének y estudiante universitaria. Entrevistador Estefanía Páez Santelices-Grimaldi. Alameda de Mariano Escobedo, Monterrey, Nuevo León.

Informante 16. (4 de noviembre de 2014). Mujer de etnia mixe y estudiante universitaria. Entrevistador Dafne Astrid Vargas Castro. Zihuakali, A. C., Monterrey, Nuevo León.

Informante clave. (9 de septiembre de 2014). Presidente de Estudiantes Indígenas de la Universidad Autónoma de Nuevo León. Entrevistador Julieta Martínez Martínez. Instalaciones de la Universidad Autónoma de Nuevo León, Monterrey, Nuevo León.

Juan Antonio Doncel de la Colina

Español, nacido en Madrid. Licenciado en Sociología y Doctor en Antropología Social por la Universidad de A Coruña (España). Es director del Centro de Estudios Interculturales del Noreste de la Universidad Regiomontana (U-ERRE). Además de investigar imparte docencia en la Facultad de Humanidades y Ciencias Sociales de la U-ERre (en las escuelas de Comunicación y de Educación). Sus publicaciones más recientes son Indígenas y educación. Diagnóstico para el nivel medio superior (2014), Once migraciones internacionales. Once comunidades de extranjeros (2015) y El mundo en Monterrey: migraciones y comunidades (2015). 